СТАТЬИ

УДК 633.3:631.67: 632.7(470.4) ФИТОСАНИТАРНЫЙ МОНИТОРИНГ В ОРОШАЕМЫХ
АГРОЛАНДШАФТАХ НИЖНЕГО ПОВОЛЖЬЯ

Комарова О.П.

ФГБНУ «Всероссийский НИИ орошаемого земледелия», Волгоград, e-mail: komarova62@rambler.ru

В статье рассмотрено влияние орошения на формирование энтомокомплексов. Показано, что орошение является одним из ведущих факторов, способствующих стабилизации фитосанитарной обстановки в агроценозах. В полидоминантных энтомологических комплексах в Нижнем Поволжье в орошаемых агроландшафтах насчитывается 1712 видов насекомых, из которых 1432 вида зарегистрированы в агроценозах и 1579 видов - в сопутствующих биотопах. Представлены данные, показывающие значительные отличия орошаемых и богарных агроценозов по метеорологическим показателям. Так, в течение вегетационного периода среднесуточные температуры воздуха в орошаемых посевах на $2-4{ }^{\circ} \mathrm{C}$ ниже в сравнении с неорошаемыми. Показано, что орошение способствует сохранению и частично расширению биоразнообразия энтомокомплексов за счет возрастания численности и видового обилия мезофильных насекомых и, в меньшей степени, гигрофильных видов. Возрастание видового разнообразия и численности мезо- и гигрофилов в посевах орошаемых сельскохозяйственных культур связано в том числе с появлением дополнительных микростаций на орошении (водосбросы, оросительные каналы, пруды-накопители и т.д.), что приводит к повышению общего разнообразия условий среды обитания насекомых. В орошаемых агроландшафтах возрастает устойчивость агроэкосистемы за счет формирования полидоминантной структуры с достаточно большим количеством входящих в нее элементов в сравнении с неорошаемыми. Наряду с отмеченным нами возрастанием биоразнообразия энтомокомплексов, в условиях орошения значительно изменяется их трофическая структура. Анализ данных сравнительных учетов численности энтомофауны показал увеличение на орошаемых посевах относительной численности хищных и паразитических видов насекомых.

Ключевые слова: энтомофауна, фитосанитарный мониторинг, видовой состав, численность, агроландшафты, орошение, Нижнее Поволжье

\title{
PHYTOSANITARY MONITORING IN IRRIGATED AGRICULTURAL LANDSCAPES OF LOWER VOLGA REGION
}

\section{Komarova O.P.}

\author{
The All-Russian scientific research institute of the irrigated agriculture, Volgograd, \\ e-mail: komarova62@rambler.ru
}

The article considers the influence of irrigation upon formation of entomocomplexes, shows that irrigation is one of the leading factors, contributing to stabilization of phytosanitary situation in agrocenosis. In polydominant entomological complexes of Lower Volga region in irrigated agricultural landscapes there are 1712 species of insects, of which 1432 species are registered in agrocenosis and 1579 species-in associated bio-topes. The data showing significant differences between irrigated and rain-fed agrocenosis according to meteorological indicators is presented. Thus, during growing season, average daily air temperatures in irrigated crops are $2-4^{\circ} \mathrm{C}$ lower in comparison to non-irrigated ones. It is shown that irrigation contributes to conservation and partly to expansion of biodiversity of entomocomplexes due to increase in number and species abundance of mesophilic insects and, to a lesser extent, hygrophilous species. The increase in species diversity and number of meso-and hygrophils in irrigated crops is associated, among other things, with the phenomenon of additional microstations in irrigation (spillways, irrigation canals, storage ponds, etc.), which leads to an increase in the overall diversity of the habitat conditions of insects. In irrigated agricultural landscapes, stability of the agroecosystem increases due to formation of a polydominant structure with a sufficiently large number of elements entering it in comparison to non-irrigated ones. Along with increase in biodiversity of entomocom-plexes noted by us, their trophic structure changes significantly in irrigation conditions. Analysing data of comparative studies of entomofauna demostrated an increase in relative number of predatory and parasitic insect species on irrigated crops.

Keywords: entomofauna, phytosanitary monitoring, species composition, number, agricultural landscapes, irrigation, Lower Volga region

Загрязнение природной среды в последние годы приобрело глобальный характер [1]. Во всех развитых странах мира в настоящее время проявляются отрицательные последствия такого загрязнения. Для контроля состояния окружающей среды одним из приоритетных направлений признано ведение экологического мониторинга, важнейшей частью которого в сельском хозяйстве является фитосанитарный мониторинг [2, 3]. Эти вопросы чрезвычайно актуальны в связи с огромными масштабами ущерба от вредных организмов, достигающего уровня 20-35, а в отдельных случаях и $100 \%[4,5]$.

В защите растений, как в России, так и за рубежом, ведется постоянный поиск нехимических способов борьбы с вредными организмами $[6,7]$. Среди актуальных направлений защиты растений на сегод- 
няшнем этапе выделяется направление экологической защиты растений, в которой основным принципом является усиление саморегулирования энтомокомплексов в основном за счет применения нехимических способов защиты посевов, при которых на поле сохраняются полезная энтомофауна и опылители. В этом случае ограниченное применение пестицидов допускается только при превышении плотности популяций вредных организмов выше экономических порогов вредоносности (ЭПВ).

Особенно важна эта проблема в условиях орошения, поскольку орошение земель, благодаря оптимизации водного режима почвы в сочетании с внесением удобрений, способствует не только повышению продуктивности сельскохозяйственных культур в 2,5-4,0 раза и более, но и активизации жизнедеятельности и вредоносности фитофагов.

Цель исследования заключается в поиске путей управления составом и структурой энтомокомплексов в орошаемых полевых севооборотах для формирования стабильных саморегулируемых энтомоценозов и, соответственно, снижения пестицидной нагрузки на агроценозы.

\section{Материалы и методы исследования}

Изучение биоразнообразия и численности насекомых в целях мониторинга фитосанитарного состояния в агроландшафтах проводились нами в 1988-2018 гг. в ФГУП «Орошаемое» (Волгоград), являющемся экспериментальной базой ФГБНУ «Всероссийский научно-исследовательский институт орошаемого земледелия». Способ полива - дождевание, режимы орошения, рекомендованные для зоны Нижнего Поволжья: для зерновых культур - предполивной порог влажности $70 \% \mathrm{HB}$, кормовых культур - 80 \% НВ.

Для изучения видового состава и динамики численности энтомофауны фитояруса и напочвенного яруса использовали соответственно метод кошения энтомологическим сачком и учета почвенными ловушками по общепринятым и усовершенствованным методикам $[8,9]$. Учеты проводили еженедельно в течение вегетационного сезона (с апреля по сентябрь). Почвы опытного участка светло-каштановые тяжелосуглинистые.

\section{Результаты исследования и их обсуждение}

Орошение в аридных условиях юга европейской части России является ве- дущим фактором, позволяющим стабилизировать фитосанитарную обстановку. Устойчивое развитие энтомоценозов здесь определяется повышением их биоразнообразия и оптимизацией трофической структуры. На орошении отмечено формирование преимущественно полидоминантных энтомологических комплексов. За годы наших многолетних исследований (1989-2018 гг.) установлено, что на европейской части России в регионе Нижнего Поволжья, охватывающем Саратовскую, Волгоградскую и Астраханскую области и Республику Калмыкия, в орошаемых агроландшафтах насчитывается 1712 видов насекомых, из которых 1432 вида зарегистрированы в агроценозах и 1579 видов в сопутствующих биотопах.

Многолетние исследования, начатые нами с 1982 г., позволили получить данные, показывающие значительные отличия орошаемых и богарных агроценозов по метеорологическим показателям. Так, параметры микроклимата, складывающегося в агроценозе люцерны, показывают значительные отличия температуры воздуха в приземном слое (до 0,5 м) орошаемых с использованием дождевания и неорошаемых посевов. Так, разница температуры воздуха в первые 3-4 дня после полива достигала $7-8^{\circ} \mathrm{C}$, в последующие дни эта разница сглаживалась, однако в течение вегетационного периода показатели среднесуточных температур воздуха в орошаемых посевах были ниже на $2-4{ }^{\circ} \mathrm{C}$ в сравнении с неорошаемыми. Вместе с тем в орошаемых посевах отмечено повышение относительной влажности воздуха на $20 \%$ внутри травостоя и заметное снижение суточных амплитуд температуры воздуха. Такое сглаживание экстремумов температуры воздухи и повышение относительной влажности в условиях орошения за счет улучшения микроклимата повышает комфортность условий обитания насекомых. Микроклимат, складывающийся внутри травостоев в условиях орошения, более комфортен для насекомых - обитателей фитояруса и герпетобия.

Таким образом, можно сказать, что орошение в аридных условиях юга России является одним из основных факторов оптимизации условий жизнедеятельности биоты агроландшафтов. Соответственно, орошение способствует сохранению и частично расширению их биоразнообразия за счет возрастания численности и видового обилия мезофильных насекомых и, в меньшей степени, гигрофильных видов. 
Подтверждением высказанного является отмеченная нами приуроченность отдельных видов насекомых, таких, например, как клубеньковые долгоносики, к определенным экологическим условиям. По нашим данным, на орошаемых участках люцерны, наряду с сухолюбивым видом Sitona crinitus Hbst., который на посевах без орошения составил $100 \%$ сборов всех клубеньковых долгоносиков, часть его экологической ниши занял вид $S$. lineatus L.

Возрастание видового разнообразия и численности мезо- и гигрофилов в посевах орошаемых сельскохозяйственных культур также связано и с появлением новых микростаций на орошении (водосбросы, оросительные каналы, пруды-накопители и т.д.), что приводит к повышению общего разнообразия условий среды обитания насекомых. Таким образом, при орошении появляются дополнительные экологические ниши для гигрофильных насекомых, которые обитают в околоводных стациях, а также для ксерофилов, концентрирующихся на неорошаемых участках, таких, например, как углы квадратов при орошении дождевальными машинами кругового действия. В результате благодаря этому в значительной степени растет биологическое разнообразие энтомокомплексов.

В целом на орошении зафиксировано формирование в основном полидоминантных энтомокомплексов, отличающихся высоким видовым разнообразием. По нашим данным, на посевах орошаемой люцерны комплекс энтомофауны насчитывает 254 вида фитофагов, энтомофагов, паразитов и опылителей. Из этого числа видов к доминирующим и субдоминирующим (не менее 5 и 2,5\% численности в структуре энтомокомплекса соответственно) относятся 12-15 видов, тогда как на неорошаемых посевах из 159 отмеченных видов преобладают 6-8.

Отмеченное благодаря орошению увеличение видового разнообразия комплексов насекомых обусловливается стабилизацией микроклиматической обстановки в агроценозах. Известно, что способность к саморегулированию и устойчивость агроэкосистемы возможна только при полидоминантной структуре с достаточно большим количеством входящих в нее элементов [5]. Тогда как в монодоминантных сообществах, имеющих невысокое видовое разнообразие, устойчивость биосистем не обеспечивается и здесь возможны вспышки численности фитофагов. В агроландшафтах с орошением, напротив, в сформированных полидоминантных энтомологических комплексах за счет усиления биоценотических связей численность вредителей, как правило, не достигает экономических порогов вредоносности.

Создание полидоминантной структуры энтомологических сообществ особенно актуально для засушливых агроландшафтов на юго-востоке России, которые находятся на стыке степной и полупустынной зон, агроценозы которых отличаются обедненностью видового состава насекомых.

Изменяющаяся в орошаемых агроландшафтах экологическая обстановка, с одной стороны, обусловливает выращивание качественно новых растений, с другой, непосредственно влияет на развитие и численность вредителей, что отражается на взаимоотношениях между фитофагом и растением, а также на биоэкологических особенностях насекомых, таких как плодовитость, выживаемость, продолжительности отдельных фаз, а также других биологических особенностях популяции.

В растениях, обеспеченных влагой, оптимизируются концентрация клеточного сока и сосущая сила листьев, что создает благоприятные условия для жизнедеятельности насекомых с колюще-сосущим ротовым аппаратом.

Так, средняя численность люцернового клопа на орошении, по данным наших многолетних исследований, выше в 4,4 раза по сравнению с обилием на неорошаемых посевах, различных видов тлей - в 3,3, цикад - более чем в 3 раза. Орошение люцернового агроценоза также положительно сказалось и на концентрации в посевах мезофильных видов насекомых. Например, численность люцерновой толстоножки на орошении возросла в 2,6 раза по сравнению с богарными посевами. Вследствие этого поврежденность семян брухофагусом увеличилась в 2,3, а суммарные потери - в 2,4 раза.

Вместе с тем хотелось бы отметить, что создание на орошаемых землях благоприятных для роста и развития растений микроклиматических условий благоприятно воздействовало на морфологические, органообразовательные, физиологические и биохимические процессы растения, что способствовало тем самым значительному росту продуктивности. При этом отмечено и более интенсивное формирование генеративных органов. В целом результаты исследований показывают рост урожайности 
семян люцерны за счет усиления репродуктивных функций растений, повышения их компенсаторных свойств. И, таким образом, несмотря на рост вредоносности фитофагов, повреждающих семена, урожайность семенной люцерны, благодаря орошению, увеличилась в 3,5 раза.

Еще одним аспектом влияния изменения микроклиматических параметров почвы и приземного слоя воздуха в условиях орошения является также и изменение фенологии как кормового растения, так и фитофагов. На орошаемых участках, как правило, продолжительность межфазных периодов увеличивается. Так, продолжительность периода до фазы созревания бобов на орошаемой люцерне по нашим наблюдениям увеличивается на 18-20 дней по сравнению с богарными посевами. При этом фенология вредителей на орошении сохраняет свою синхронизацию с фенологическим циклом кормового растения, удлиняясь в среднем до 20-25 дней. Увеличение периода активного питания как личинок и взрослых особей люцернового клопа, так и личинок фитономуса в условиях растянутости за счет орошения фаз ветвления и бутонизации растений, а также удлинение длительности фазы созревания семян, к которой приурочена откладка яиц люцерновой толстоножкой и желтым тихиусом, привела к росту вредоносности всех изучавшихся видов вредителей на 30-40\% по сравнению с неорошаемым вариантом.

Орошаемые посевы являются также более благоприятным местом обитания для хищных и паразитических насекомых, выполняющих благодаря уничтожению вредителей роль биологической защиты от колюще-сосущих и других вредных для посевов насекомых. Как уже было отмечено, в связи с расширением параметров экологической валентности, а также за счет появления новых экологических ниш и возрастания разнообразия условий в условиях орошения увеличивается видовое обилие энтомофагов, паразитов и опылителей, в числе которых важную роль в качестве полезного компонента энтомокомплексов играют энтомофаги напочвенного яруса. Данные учетов ловушками Барбера показывают, что в среднем за вегетационный сезон на различных культурах численность герпетобионтов в орошаемых агроценозах оказалась в 2,5-12,4 раз выше, чем на богарных вариантах. По нашим данным, в комплексах напочвенных энтомофагов преобладали по численности хищники из семейства жужелиц (Carabidae). В комплексе напочвенной фауны на орошении представители этого семейства составляли $82,1 \%$, а на неорошаемых - 85,02\%.

При этом следует отметить, что на орошаемых посевах в первую очередь численность жужелиц возрастала за счет увеличения численности видов со смешанным типом питания, таких как Poecilus cupreus L., Harpalus (pseudoophonus) rufipes Deg., Bembidion properans Steph., Clivina fossor L., Poecilus nitens Shaud., Harpalus distinguendus Duft. По данным карабидологов, все эти виды жужелиц отмечены как активные хищники фитофагов в агроценозах $[8,9]$. И можно говорить о том, что увеличение суммарной плотности жужелиц является одним из наиболее положительных результатов воздействия орошения на карабидофауну.

Основными причинами возрастания обилия полезной биоты под влиянием орошения можно считать значительное изменение микроклимата в фитоярусе и напочвенном ярусе посевов сельскохозяйственных культур в сторону повышения мезофитности, что увеличивает количество экологических ниш для энтомофагов и паразитов, подавляющее большинство которых предпочитают мезофитные и гигрофитные биотопы. Кроме того, в орошаемых агроценозах значительно возрастает общее число беспозвоночных, многие из которых являются кормовой базой для хищников и паразитов $[10,11]$. Таким образом, общее увеличение численности энтомофагов при орошении, кроме благоприятного микроклимата, обусловлено также и достаточным количеством питания.

Наряду с отмеченным нами возрастанием биоразнообразия энтомокомплексов, в условиях орошения значительно изменяется их трофическая структура. Анализ данных сравнительных учетов численности энтомофауны показал увеличение на орошаемых посевах относительной численности хищных и паразитических видов насекомых. Так, соотношение общей численности энтомофагов и фитофагов составляет здесь 1:1,9, а в неорошаемых условиях оно увеличивается до 1:6,1. При отмеченном соотношении тлевых (божьих) коровок и фитономуса на орошаемых посевах $(1: 0,1)$ хищники полностью уничтожают вредителя. В условиях орошения наблюдается также оптимальное соотношение между численностью энтомофагов (хищные клопы набисы и ориусы, личинки 
златоглазок, сирфид) и растительноядных клопов - 1:9. При этом оптимальным считается такое соотношение, когда на одного хищника приходится не более 13 личинок растительноядных клопов [12]. На основании этих данных можно сделать вывод, что в данном случае популяция слепняков подавляется энтомофагами.

На орошаемых посевах соотношение энтомофагов (хищные клопы, златоглазки) и клубеньковых долгоносиков не выходит за пределы 1:0,5. При таком соотношении осуществляется подавление численности вредителя [12]. Соотношение энтомофагов (кокцинеллиды, личинки златоглазок, сирфид, хищные клопы) и тлей колеблется от 1:4,2 до 1:6,6, что позволяет хищным насекомым снижать численность афидиид до хозяйственно неощутимого уровня.

На неорошаемых посевах при значительном ухудшении соотношений между энтомофагами и вредителями (по фитономусу $1: 1,9$; растительноядным клопам - 1:19,7; тлям - 1:16,6; клубеньковым долгоносикам - 1:7) естественного регулирования численности вредителей не происходит и при превышении численности фитофагов показателей экономических порогов вредоносности необходимо применение пестицидов для защиты посевов от вредных насекомых.

\section{Заключение}

В результате исследований отмечено возрастание в условиях орошения сбалансированности агроэкосистем, их способности к саморегуляции. Стабильность энтомокомплексов агроценозов, что как раз и является целью экологизированной защиты растений, обеспечивается за счет формирования полидоминантных энтомологических комплексов с высоким биоразнообразием и оптимизации их трофической структуры. Несмотря на то, что на орошении зафиксировано увеличение численности фитофагов, на орошаемых посевах складывается более благоприятное соотношение между энтомофагами и вредителями, благодаря чему появляется возможность саморегулирования энтомофауны за счет усиления активности энтомофагов. Тем самым создается реальная возможность сохранения урожая и снижения на орошаемых посевах кормовых культур пестицидной нагрузки на 40-50 \%.

\section{Список литературы / References}

1. Семеренко С.А. Экология и защита растений // Масличные культуры. Научно-технический бюллетень Всерос- сийского научно-исследовательского института масличных культур. 2015. № 4 (164). С. 103-137.

Semerenko S.A. Ecology and plant protection // Maslichnye kul'tury. Nauchno-tehnicheskij bjulleten' Vserossijskogo nauchno-issledovatel'skogo instituta maslichnyh kul'tur. 2015. № 4 (164). P. 103-137 (in Russian).

2. Долженко В.И. Фитосанитарное районирование вредных для сельского хозяйства организмов // «Агротехнический метод защиты растений от вредных организмов». Материалы V международной научно-практической конференции. 13-17 июня 2011 г. Краснодар: КубГАУ, 2011. C. 24-30.

Dolzhenko V.I. Phytosanitary zoning of organisms harmful to agriculture // «Agrotehnicheskij metod zashhity rastenij ot vrednyh organizmov». Materialy V mezhdunarodnoj nauchno-prakticheskoj konferencii. 13-17 ijunja 2011 g. Krasnodar: KubGAU, 2011. P. 24-30 (in Russian).

3. Подгорная М.Е., Якуба Г.В., Холод Н.А., Черкезова С.Р., Прах С.В., Талаш А.И., Мищенко И.Г. Закономерности формирования энтомо-акаро-патосистем многолетних насаждений под влиянием абиотических и техногенных факторов и фитосанитарный мониторинг // Научные труды Северо-Кавказского зонального научно-исследовательского института садоводства и виноградарства. 2015. Т. 7. С. 159-166.

Podgornaja M.E., Jakuba G.V., Holod N.A., Cherkezova S.R., Prah S.V., Talash A.I., Mishhenko I.G. Regularities of formation of entomo-acaro-pathosystems of perennial plantings under the influence of abiotic and technogenic factors and phytosanitary monitoring // Nauchnye trudy Severo-Kavkazskogo zonal'nogo nauchno-issledovatel'skogo instituta sadovodstva i vinogradarstva. 2015. T. 7. Р. 159-166 (in Russian).

4. Захаренко В.А. Рынок пестицидов в России и перспективы его развития // Защита и карантин растений. 2014. № 11 . C. $3-6$.

Zakharenko V.A. Pesticide market in Russia and prospects of its development // Zashhita i karantin rastenij. 2014. № 11. P. 3-6 (in Russian).

5. Чернышев В.Б. Экологическая защита растений. Членистоногие в агроэкосистеме: учебное пособие. М.: Изд. МГУ, 2001. $136 \mathrm{c.}$

Chernyshev V.B. Environmental protection of plants. Arthropods in the agroecosystem: a textbook. M.: Izd. MGU, 2001. 136 p. (in Russian).

6. Артохин К.С. Метод кошения энтомологическим сачком // Защита и карантин растений. 2010. № 11. С. 45-48.

Artohin K.S. Entomological sweep-net method // Zashhita i karantin rastenij. 2010. № 11. P. 45-48 (in Russian).

7. Mykhailenko I.L., Smetana O.M. Method to study soil mesofauna as part consortium ecosystem // Pitannja bioindikaciï ta ekologiï. 2014. № 19-1. P. 151-156 (in Ukrainian).

8. Мелихов В.В., Комаров Е.В., Комарова О.П. Орошение - основа повышения стабильности энтомоценозов в аридных условиях Юго-Востока России // Вестник Казанского государственного аграрного университета. 2019. T. 14. № 1 (52). C. 34-39. DOI: $10.12737 /$ article_5cced ba9876757.12168511.

Melikhov V.V., Komarov E.V., Komarova O.P. Irrigation is the basis for increasing the stability of entomocenoses in arid conditions of the South-East of Russia // Vestnik Kazanskogo gosudarstvennogo agrarnogo universiteta. 2019. T. 14. № 1 (52). P. 34-39 (in Russian).

9. Friche T., Egerer S., Matezki S., Pick Ch., Wogram J. 5-Point programme for sustainable plant protection. Environmental Sciences Europe. 2018. Vol. 30. Article 8. DOI: 10.1186/ s12302-018-0136-2.

10. Комаров Е.В., Калюжная Н.С., Черезова Л.Б. Состав и структура сообществ жесткокрылых насекомых (Coleoptera) как показатель состояния степных экосистем Юго-Востока европейской части России // «Степи северной Евразии: стратегия сохранения природного разнообразия и степного природопользования в XXI веке». Материалы международного симпозиума. Оренбург: Институт степи УрО РАН, 2000. С. 189-190. 
Komarov E.V., Kaljuzhnaya N.S., Cherezova L.B. Composition and structure of Coleoptera communities as an indicator of the state of steppe ecosystems in The South-East of the European part of Russia// «Stepi severnoj Evrazii: strategija sohranenija prirodnogo raznoobrazija i stepnogo prirodopol'zovanija v XXI veke». Materialy mezhdunarodnogo simpoziuma. Orenburg: Institut stepi UrO RAN, 2000. P. 189-190 (in Russian)

11. Комаров Е.В., Карпова Т.Л. Состав, структура, распределение комплексов герпетобионтных жесткокрылых (Coleoptera) в орошаемом агроландшафте // Фундаментальные исследования. 2014. № 12-11. С. 2350-2356.
Komarov E.V., Karpova T.L. Composition, structure, distribution of herpetobiont Coleoptera (Carabidae) in irrigated agricultural landscape // Fundamental research. 2014. № 12-11. P. 2350-2356 (in Russian).

12. Демчук А.Т., Дядечко Н.П., Рубан М.Б. Трипсы на посевах семенной люцерны // Интегрированная защита растений от вредителей и болезней с.-х. культур: сборник научных трудов УСХА. Киев, 1983. С. 11-13.

Demchuk A.T., Djadechko N.P., Ruban M.B. Thrips on seed alfalfa crops // The integrated protection of plants against wreckers and diseases of agricultural cultures: collection of scientific works USHA. Kiev, 1983. P. 11-13 (in Russian). 